\title{
Computation of the Sampling Distribution of Coherence Estimate
}

\author{
SARALEES NADARAJAH ${ }^{1}$ and SAMUEL KOTZ $^{2}$ \\ ${ }^{1}$ University of Nebraska, Lincoln, Nebraska 68583, USA \\ ${ }^{2}$ George Washington University, 2121 Eye street, NW Washington, D.C. 20052, USA
}

Manuscript received on May 23, 2006; accepted for publication on May 24, 2006; presented by MARTIN SCHMAL

\begin{abstract}
The recent paper published by Miranda de Sa (2004) derived, for the first time, the sampling distribution of coherence estimated between two signals. The paper also considered computational issues of the sampling distribution, using an approximate method. In this short note, we provided several 1-line programs for the exact computation of various measures of the sampling distribution. The advantages of using these programs are discussed.
\end{abstract}

Key words: coherence estimate, non central beta distribution, R language, sampling distribution.

\section{INTRODUCTION}

The recent paper by (Miranda de Sa 2004) derived, for the first time, the sampling distribution of the coherence estimate between one random and one periodic signals. If $\hat{\kappa}_{y}^{2}(f)$ denotes the coherence estimate then it was shown that

$$
\hat{\kappa}_{y}^{2}(f) \sim \operatorname{nbeta}\left(1, M-1, \frac{2 M \kappa_{y}^{2}(f)}{1-\kappa_{y}^{2}(f)}\right),
$$

for some parameters $M$ and $\kappa_{y}^{2}(f)$, where “ " denotes "is distributed as," and $\operatorname{ncbeta}(p, q, \lambda)$ denotes the non central beta distribution with shape parameters $p$ and $q$ and non centrality parameter $\lambda$. The probability density function (pdf) of $\operatorname{ncbeta}(p, q, \lambda)$ is given by

$$
f(x)=\frac{x^{p-1}(1-x)^{q-1}}{\Gamma(q)} \exp \left(-\frac{\lambda}{2}\right) \sum_{k=0}^{\infty} \frac{\Gamma(p+q+k)(\lambda x)^{k}}{\Gamma(p+k) 2^{k} k !}
$$

for $0 \leq x \leq 1$. We refer the reader to (Johnson et al. 1995) for detailed properties of (2).

Correspondence to: Saralees Nadarajah

E-mail: saralees.nadarajah@manchester.ac.uk 
The result in (1) is potentially very useful because the coherence estimate has applications in many areas of the sciences and engineering, e.g. medical and biological engineering, computing, signal processing and acoustics. Thus, it is important that flexible computational methods are provided to compute (2) and its measures. The computational methods described in (Miranda de Sa 2004) are based on an approximation of the non central beta distribution due to (Patnaik 1949). Here, we provide 1-line programs for the exact computation of various quantities of interest of the non central beta distribution given by (2) for all applicable values of $p, q$ and $\lambda$. These programs are written in R, a statistical software freely downloadable from http://www.r-project.org/ due to (Ihaka and Gentleman 1996). We expect that these programs could be widely used in the sciences and engineering.

\section{PROGRAMS}

Here, we provide five programs in $R$ for computing (2) and its measures. The program names and their values are as follows: $\operatorname{dbeta}(\mathrm{x}, \mathrm{p}, \mathrm{q}$, lambda) returns the value of the pdf, $f(x)$, given by (2) for given $x$ and $(p, q, \lambda)$; ex(n, p, q, lambda) returns the value of the $n$th moment defined by

$$
E\left(X^{n}\right)=\int_{0}^{1} x^{n} f(x) d x
$$

where $f(\cdot)$ is given by (2), for given $n$ and $(p, q, \lambda)$; $\operatorname{pbeta}(\mathrm{x}, \mathrm{p}, \mathrm{q}$, lambda) returns the value of the cumulative distribution function (cdf), $F(x)$, defined by

$$
F(x)=\int_{0}^{x} f(t) d t
$$

where $f(\cdot)$ is given by (2), for given $n$ and $(p, q, \lambda)$; qbeta(u, $\mathrm{p}, \mathrm{q}$, lambda) returns the value of the inverse function $F^{-1}(u)$ defined by

$$
F\left(F^{-1}(u)\right)=u
$$

for given $u$ and $(p, q, \lambda)$; rbeta $(\mathrm{n}, \mathrm{p}, \mathrm{q}$, lambda) generates $n$ random numbers from the non central beta distribution for given $n$ and $(p, q, \lambda)$.

dbeta $(x$, shape $1=p$, shape $2=q, n c p=1$ ambda $)$

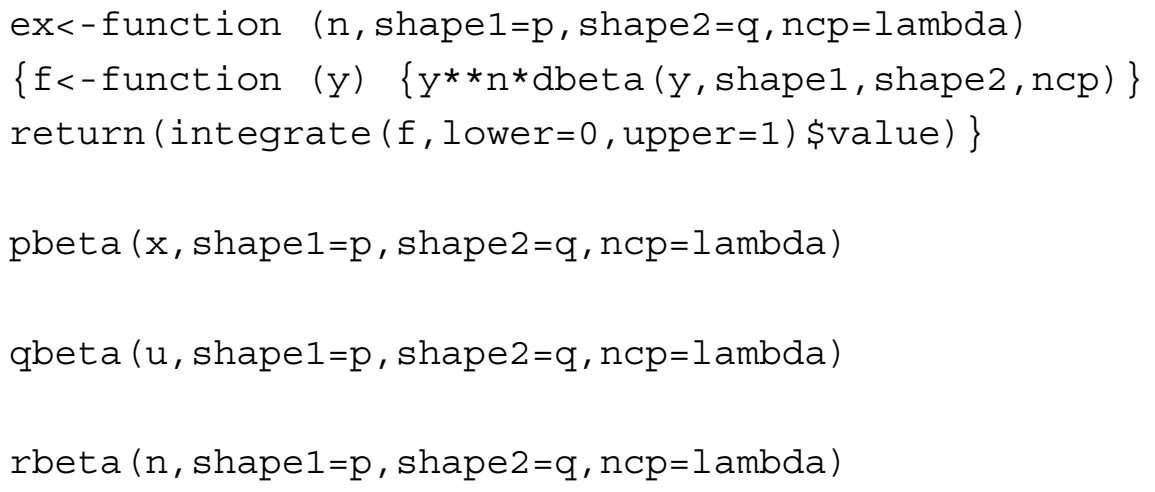




\section{ADVANTAGES}

We have provided five programs in $\mathrm{R}$ for the exact computation of the sampling distribution of the coherence estimate between two signals. These programs have several advantages because:

a) there are no restrictions on the input parameters $p, q$ and $\lambda$;

b) the programs are only 1-line long (except for one);

c) additional measures of the sampling distribution derived;

d) the programs are easy to implement;

e) the software is freely available (unlike Matlab) on any platform;

f) the programs avoid the need for any approximation.

\section{ACKNOWLEDGMENTS}

Saralees Nadarajah is a Senior Lecturer in the School of Mathematics, University of Manchester, UK. His research interests include climate modeling, extreme value theory, distribution theory, information theory, sampling and experimental designs, and reliability. He is an author/co-author of four books, and has over 300 papers published or accepted. He has held positions in Florida, California, and Nebraska. Samuel Kotz is Distinguished Professor of Statistics in the Department of Engineering Management and Systems Engineering, George Washington University, Washington, D.C., USA. He is the senior co-editor-in-chief of the thirteen-volume Encyclopedia of Statistical Sciences, an author or co-author of over 300 papers on statistical methodology and theory, 25 books in the field of statistics and quality control, three Russian-English scientific dictionaries, and co-author of the often-cited Compendium of Statistical Distributions.

\section{RESUMO}

O presente trabalho publicado por Miranda de Sá (2004) derivou pela primeira vez, a distribuição de amostras de coerência estimada entre dois sinais. Este artigo apresenta temas computacionais relacionados a distribuição de amostras, utilizando métodos de aproximação. Nesta nota, apresentamos vários programas "on line" computação exata de medidas de distribuição de amostras. São discutidas as vantagens destes programas.

Palavras-chave: coerência estimativa, distribuição beta não centralizada, linguagem $R$, distribuição de amostras.

\section{REFERENCES}

IHAKA R And Gentleman R. 1996. R: A language for data analysis and graphics. J Comput Graph Stat 5: 299-314. 
JoHnSON NL, Kotz S AND BALAKRIShnAN N. 1995. Continuous Univariate Distribution, volume 2, $2^{\text {nd }}$. ed., J Wiley \& Sons, New York.

MirandA DE SA AMFL. 2004. A note on the sampling distribution of coherence estimate for the detection of periodic signals. IEE Signal Proc Lett 11: 323-325.

PATNAIK PB. 1949. The noncentral $\chi^{2}$ - and $F$ - distribution and their applications. Biometrika 36: 202-232. 